\title{
Introduction: in search of alternative origins of organizing
}

\section{Tuomo Peltonen, Hugo Gaggiotti and Peter Case}

How might we imagine the origins of organizing? We trust that most readers of this volume will agree that this is a thought-provoking and challenging question. Are we to anchor the origins of organizing to specific historical events, to particular philosophical concepts or, rather, should we locate them firmly within familiar (and safe) disciplinary traditions? We take as our point of departure an admixture of all three in this introductory chapter, that is, historical, philosophical and disciplinary origins. From this perspective, perhaps the most dominant idea in the mainstream historiography of management and organization is that systemic organizing started to take hold in the Western hemisphere sometime in the mid-1800s (Barley and Kunda, 1992; Reed, 2006: Starbuck, 2003). This was the time when the practice of industrial management began to enter the general consciousness of economic life of the time (Bendix, 1974; Guillén, 1994). Indeed, a related convention is to understand theoretical reflection on organizing as appearing in the aftermath of the industrial management approaches pioneered by, inter alia, F.W. Taylor, Henri Fayol and their disciples. Despite the accumulating body of research on the birth of organization theory (OT; e.g. Adler, 2009), there have been astonishingly few contributions that challenge the established consensus of the social and philosophical ideas marking the origin of organizational studies. Typical assessments begin from Taylor, Fayol and Weber, continuing to the works of Mayo, Roethlisberger, Barnard and onwards to the first generation of selfconscious sociologists of organizations (Wren and Bedeian, 2009; Hatch and Cunliffe, 2006). Even when there were attempts to expand this predominantly Western narrative, one could argue that the investigations reoriented their attention only minimally in terms of the temporal (Jacques, 1996) or institutional (Drucker et al., 1995) focus adopted.

While the practical doctrine of programmatic organizing is identified with the rise of scientific management, social theoretical reflection on the 
phenomenon of formal organizations is seen as having originated alongside Weber's articulations about the role of the bureaucratic organizational form as an embodiment of a rational-legal justification of institutional authority (Hinings and Greenwood, 2002). Linking the origins of organizing to the emergence of the principles of industrial management and associated sociological reflections on the meaning of formalistic, rational modes of organizing has become the cornerstone of a consensus historical narrative (White, 1973) regarding the evolution of organizational theory and praxis. For example, Tsoukas (2003) argues that the early understanding of organizing as a feature of rigid bureaucratic organizations has paved the way for more sophisticated conceptualizations; where organization is seen as a complex outcome of heterogeneous and contested processes of organizing. Similar narratives appear in the writings of authors such as Casey (2002), Hatch and Cunliffe (2006), Morgan (1986) and Scott and Davis (2006).

The historiographical interpretation of (modern) organizing - having its origin in the emergence of formal organizations and associated rational techniques of managing - leads to a construction of the field that emphasizes the triumph of theoretical and practical openness towards the complexities and multiplicities inherent in the process of organizing. The organizational studies community has succeeded in overcoming its formalistic beginnings, fostering a more dynamic, interactive and creative image of organizational life.

However, postulating origins of organizing as associated with the ascent of scientific management and bureaucratic rationality is not the only historiographical story in town. Already by 1968, George claimed that the rudimentary foundations of organizing could be found in the earliest civilizations of Asia, Africa and Europe. Continuing from ancient civilizations to medieval times - and eventually to the modern period of capitalism and science - George tracks the gradual awakening of the awareness for the need for systemic management. He identifies a series of historical advances that, taken together, contribute to the multifaceted understanding of rational organizing. George's insistence on extending the search for the potential origins of organizing earlier than the assumed landmark of the late nineteenth century has been since then elaborated and developed by several scholars. For example, Wren and Bedeian (2009) and Witzel (2012) have introduced a longer historical arch of management thought in their comprehensive works. Their writings are intended to highlight the pre-modern and non-Western notions of organizing and managing, positioning these alongside more established understandings that emanate from the landscape of the Enlightenment and the Industrial Revolution in the developed economies of the West. Kieser 
(1987, 1989), on the other hand, has offered a detailed analysis of late-medieval human groupings, such as those found in monasteries and craft guilds, which positions them as nascent forms of modern organizing that affect the structuring of institutional realities; forms that emerge long before the appearance of the capitalist corporation and governmental bureaucracies.

The search for alternative historical origins for organizational theory and for practices of organizing has often been pursued alongside a quest for expanding the cultural sources of ideas and philosophical foundations for organizing. These lines of enquiry invariably necessitate a widening of focus beyond that of the Western world. The work of cross-cultural scholars, who aimed to demonstrate how primary beliefs and assumptions about organizational reality are irrevocably moulded by the cultural meanings innate to the local societal context (Hofstede, 1983; Laurent, 1986), is germane in this regard. Instead of universalizing apparently Western ideas about reason, individuality and freedom, organizational scholars embarked on a project of trying to research different understandings of social reality from indigenous perspectives. This, in turn, expanded, in places, into a more general theoretical quest for philosophical, ethical and psychological insights of non-Western civilizations and introduced thus alternative points of departure in conceptualizing and imagining organizing (e.g. Case and Brohm, 2012; Chia, 2003).

If the mainstream historiography lays out a story of increasing sophistication and openness developing from formalistic and rational beginnings, alternative accounts place greater emphasis on the foundational roots to be found in non-Western histories and philosophies. Here, the evolutionary arch of mainstream historiography is replaced with a cyclical image of history; where a revelation of the new origin is thought to legitimate an unproblematic bridging of the present with the past. The foundations of organizing are affirmed by the novel discovery of an alternative beginning. However, this type of extension of the historical roots of organizing and managing could lead to anachronism (Jacques, 2006): the tendency to falsely impose imagined features into an understanding of a historical epoch or event. Often this takes the form of interpreting the past from the perspective of contemporary topics and presuppositions, leading to a related bias known as presentism (Spoerhase, 2008). Skinner (1969), for example, warns of the propensity of historians to unwillingly promote a particular ideology or dogma by claiming to have found the seeds of a prevailing contemporary doctrine in the actions and discourses of a bygone era. Similarly, Foucault in his archaeologies (1972), as well as Kuhn (1962) in his inquiries into the 
history of science, demonstrate how schools of thought tend to develop through discontinuous shifts from one epistemic discourse to another.

In histories of organizing, anachronistic and presentist readings tend to assume that historically distant periods or actors would have understood their own practice and thought as corresponding to the language of organizations and management evident in the contemporary discourses and theories (cf. Cummings and Bridgman, 2011; Mills et al., 2014). By extending the search for origins in this way, one faces the challenge of understanding the worldviews of cultures and civilizations that differ substantially from those of the present epoch of late modernity. Revisiting pre-modern societies and their approaches to organizing, one needs to consider the extent to which the idea of order as emanating from everyday social interaction was seen as a valid understanding in the metaphysical and ideological context of the milieu in question. Indeed, concepts like 'management' that we now take for granted as integral to modern organization might have had little or no relevance for the social self-understandings of the more distant ages.

For example, Dobbs (2013) has criticized Witzel's (2012) recent extended historiography for lacking contextual sensitivity for the radically different ontological and epistemological set-ups of pre-modern civilizations. He reminds the reader that instead of recognizing the legitimacy of the contemporary system of meritocratic careers and the relational interdependence between the manager and the employees, pre-industrial societies were generally built on the basis of the belief in the other-worldly superiority of the aristocratic class. The ruling elite had special access to divine truths and was therefore afforded unquestioned authority to govern. Matters relating to work and commerce were seen as being the lowly province of secular existence, compared to the pursuit of divine guidance through the continuity of the quasi-theocratic regimes. For Dobbs (2013), going beyond the industrial era requires a consideration of the societal and philosophical frameworks that depart radically from our own rationalistic and democratic principles.

The challenge of alternative historiographies, then, is to carefully craft an understanding of organizing that is not so overtly universalist as to falsely interpret ancient epochs and civilizations as embryonic manifestations of the present zeitgeist. As a recurring theme, organizations and organizing could have existed in some form even before the Industrial Revolution, but a historian should avoid the temptation of imposing his or her own presentist interpretations onto epochs where the basic understandings of order, authority, work and human condition differed substantially from those of the contemporary world. At the same time, it would not be fruitful to turn back to the other extreme, where organizing 
would be imagined solely as the product of the developments and functional prerequisites of the Industrial Revolution and the emergence of rational modernity. This would entail a considerably narrower definition of organizing, organizations and managing, which would again lock the discussion of origins to the immediate societal and cultural contexts informed by the ethnocentric prejudices of Western, modernistic values and beliefs.

In this book, we explore previously unrecognized or marginalized origins of OT and organizing through alternative ways of excavating and interpreting the past. By so doing, we highlight the overt influence that particular ideas have had historically on the foundations of organization. At the same time, we also emphasize the emancipatory or ethical potential of philosophies, worldviews and cultural practices that have been so far excluded from the category of 'authorized origins' within organizational and management studies. We aim to promote a sense of openness to the quest for origins in organizational practice and theory by foregrounding the concept of organizing. As an idea in contemporary OT, organizing has its genesis in the work of scholars such as Weick (1969) who, almost 50 years ago, advocated a more processual understanding of organizations as delicate achievements brought about through ongoing sensemaking, interaction and practical engagement in various institutional contexts. His original contribution marked an early initiative that presaged a series of steps taken in recent decades to liberate organization studies from the conception of organizations as formal administrative units that require a system of hierarchical structuring and a division of labour for their effective functioning (cf. Czarniawska, 2014).

A focus on organizing brings with it the possibility of relaxing some of the assumptions related to organizations and organization theory in favour of a more unprejudiced search for alternative beginnings. The concept enables one to understand a wide array of social and cultural practices as activities aimed at delivering a degree of order to the collective pursuits across the substantive contexts of work, commerce and public services. It allows one to examine those initiatives that lead to cohesive communities as well as those that eventually lead to a more flexible and dynamic arena for human endeavour. Moreover, organizing is not exclusively reserved for material practices, but can also involve the organization of ideas, discourses and images in the minds of subjects participating in collective projects. Organizing is a heterogeneous and open-ended process, more an instance in the continuous struggle for regularity and patterning than a stable order of things. 


\section{OUTLINE OF THE CHAPTERS}

The book is presented in two parts. Part I of the collection begins with Gibson Burrell's compelling and, dare we say, intentionally 'chaotic' exploration of the relationship between Chaos and organization. In typically contrarian style, Burrell insists that Chaos be given priority over organization if we are to gain fresh insight into the relationship and tension between these two opposites. His espoused purpose in this chapter is to 'patrol the edge of Chaos' and expose it as 'the absent presence which makes organization possible'; a sine qua non that OT tends 'always and everywhere to ignore'. In effect, Burrell forces Chaos to go head to head with the organon, the latter being a Latin term (of Greek derivation) that Burrell selects precisely for its manifold semantic connotations and resonances. Whilst cautioning against an uncritical pursuit of 'origins', he nonetheless selects three sources of organization in human history for particular attention, namely (a) narrative accounts and emplotment that gave rise to the myths of organization; (b) social music-making, which led to the development of musical instruments and crucially, in the Western tradition, to organs; and (c) the incessant pursuit of ever sharper metal tools with which humans could leave marks on the world. The seemingly chaotic (dis)organization of the chapter is, we assume, Burrell's reflexive - and entirely apposite - gesture toward self-exemplification. Readers are treated to an intellectual tour de force that sees appearances, inter alia, of the (bi-directional) cosmogenic myths of the world's major religions and civilizations, a critique of the fashionable interest in 'chaology' (scientistic Chaos Theory which seeks, in essence, to 'strangle Chaos at birth'), a close interrogation of the semantics of organization and a rendering of the genealogy of OT. It is a chapter that veritably fizzes with insight and imagination and which culminates in a political manifesto promoting a putative 'cult of Chaos'. This cult would need, by definition and in practice, to be 'marginalized and unrecognized in Organization Theory'. As Burrell has it, 'we must retain the notion of "Chaos" as free (not only from the chaologists) but from those who wish to occupy it with societal ruptures, everyday poor organization and military destruction'.

Continuing with a set of chapters focusing on a particular theoretical tradition as an alternative origin for understanding organizations and organizing, Tuomo Peltonen in his contribution poses a strident challenge to the accepted historiography of OT. In particular, he draws attention to the relative neglect of the Russian-born scholar Pitirim Sorokin. The 
widely accepted narrative of the origins of OT acknowledges the practitioner stories of F.W. Taylor and Henri Fayol, highlights the emergence of a nascent social science community at Harvard University and reinforces an established litany concerning the foundation and early days of its Business School at the beginning of the twentieth century. The likes of Mayo, Roethlisberger, Barnard and Merton, for instance, have become iconic in this historical account, as have other key members of the Harvard circle, such as Henderson, Homans, Whitehead and, perhaps most significantly, Talcott Parsons. Parsonian functionalist sociology, Peltonen maintains, unjustifiably overshadows the work of Sorokin, whose studies of the long cycles of cultural mentalities within civilizational epochs has, despite its contemporary relevance, been largely overlooked. Beginning with a fascinating overview of Sorokin's biography, Peltonen goes on to provide a compelling account of why Parsonian sociology came to prevail over Sorokinian sociology. Aside from the intrinsic appeal of the functionalist model - a theory intellectually and politically ripe for its time - Parsons was a far more sociable and inspirational figure in the eyes of his younger Harvard colleagues (most notably Robert Merton). Sorokin, by contrast, cast a rather solitary figure who worked independently and whose theories were at a more mature stage of development than Parsons'. Similarly, whereas Parsons' systems thinking drew the attention of organization scholars within an embryonic Harvard Business School, Sorokin's writing on the history of civilizational forms simply did not find any traction with these colleagues. Despite being ignored in this way, his revelations concerning the transformations between what he termed 'Ideational', 'Sensate' and 'Idealist' periods in the development of Western culture - i.e., an analysis of the complex transitions between classical Greek, Roman, medieval, Renaissance, Enlightenment and contemporary capitalist modernity - are, Peltonen insists, highly germane to OT. Sorokin's work on cycles of institutional evolution and involution, for instance, anticipates by several decades Barley and Kunda's studies of the history of management rhetoric as an unfolding of the alternating periods of normative and rational discourses. Similarly, the centrality of metaphysics and religion within Sorokin's oeuvre is highly salient to many of the current debates in the field of workplace spirituality. Overall, Peltonen argues that the existence of Sorokin's civilizational and trans-disciplinary theory in the Harvard social science milieu disrupts the prevailing periodization and classifications inherent in OT. In so doing, he reveals certain tacit limits of the field and its canonical historical narratives that have so far gone unrecognized in the scholarly community. 
Staying within the early days of modern OT, Hugo Gaggiotti, Monika Kostera and Paweł Krzyworzeka revisit the role of anthropology in the genesis and development of academic organization studies. Rather than approaching anthropology as a methodological tool for the qualitative study of organizing and culture, they advocate a considerably broader theoretical relevance for anthropological and ethnographic inquiry in the midst of the ongoing discussions about the status and future of organizational analysis. This relevance is demonstrated, they argue, in the prominent influence of anthropology in the early phases of OT under the auspices of Harvard University and its Business School. The famous Hawthorne studies conducted by Elton Mayo and his team appropriated and applied methods directly from the anthropological tradition of the day. The impetus for a more ethnographic approach to social organization at the Hawthorne plant came from Lloyd Warner, a pioneering anthropologist who subsequently influenced later observational methods and cultural interpretations of groups at work. For example, the celebrated bank-wiring department study was a direct outcome of Warner's insistence on an ethnographic approach to uncovering the social structures and norms in the everyday life of a manufacturing plant. The evolving academic organization studies field, however, largely dismissed the potential of anthropology for informing the ensuing efforts to understand, conceptualize and interpret organizing. Gaggiotti et al. propose a number of reasons for the eventual marginalization of the anthropological perspective in organization studies. Firstly, during the Hawthorne studies, Elton Mayo suppressed the findings from ethnographic description that were hostile to the idea of managerial control and, in the context of academic politics, might have jeopardized the corporate and foundational support for the large-scale investigation. Secondly, the professional anthropologists distanced themselves from the idea of the factory or physical site as the unit of analysis. This is demonstrated most acutely by the move of Lloyd Warner to embrace the whole industrial town as a more compact and integrated setting for holistic ethnographic work, the shift that led to the influential Yankee Town studies under the leadership of Warner. As a result, the authors contend, the full potential of anthropology as a comprehensive paradigm of understanding organizing has not been embraced in the ensuing development of organization studies. Echoing the call of C. Wright Mills to practise sociological imagination in enlightened inquiry, Gaggiotti et al. provide a vision for future scholarship which fully embraces interpretative ethnographic enquiry in the spirit of Warner and Whyte.

Caterina Bettin and Albert Mills shift the discussion to the work of philosopher Simone de Beauvoir, whose ideas are rarely seen as a 
mainstay in organizational theorizing. Being significantly ahead of her time, de Beauvoir understood individual subjectivity as an outcome of socio-material structures and processes, much in the same way as poststructuralists and Marxists. Nevertheless, in her philosophy, individuals are still capable of exercising their situated and embodied agency in the midst of seemingly constraining contexts. In their chapter, Bettin and Mills contrast de Beauvoir's work with that of her well-known partner and fellow existentialist, Jean Paul Sartre. Whereas Sartre was an advocate of a more individualistic and self-contained image of the self, de Beauvoir maintained that human freedom cannot be conceived as independent of social (or organizational) contexts. An archetypical case of the social situation limiting the pursuit of freedom is the positioning of women as Others of the male regime of autonomous selfhood. Resonating with the structure-agency debate, Bettin and Mills contend that a de Beauvoirian understanding of subjectivity retains a sense of existential and phenomenological autonomy for the subject to create the conditions for his or her life, while at the same time acknowledging that there are real limits for human freedom in terms of oppressive social and organizational structures. However, the struggle between freedom and submission is not a dialectic between abstract domains of structures and subjects, as for example in Giddens' structuration theory. The notion of the 'art of living' denotes the practical and open-ended character of the struggle for one's particular life project in the context of oppressive and alienating structures. As Bettin and Mills demonstrate through a reading of two cases of working with ambiguity in personal quests for space for freedom, there is no ready-made transcendental form of deep human subjectivity that can be tapped into in periods of crisis. Freedom is a reflexive and situated process: a journey rather than a destination. Controversially, Bettin and Mills suggest it is this request for all humanity to engage with active arts of living that might be the reason why the contribution of de Beauvoir to a more general theory of the self and the social has not been widely endorsed among critical and sociological organization scholars.

Part II of the book engages with various historical origins of organizing. In her suggestive and scholarly chapter, Barbara Czarniawska gives us the opportunity to imagine the origins of organizing in the still significant legacy (at least in Europe) of the Romans and their longlasting empire. Her thoughts start with a provocative rationale as to why the Roman Empire is relevant to reflect upon with regard to archetypal images of organizing - the rise, the fall, the strategy, the expansion and so forth - and why the Roman civilization still permeates much of our organizational imagination. Her reflections are not so much concerned 
with the organizational and economic aspects of the Empire, but of the imbricated relationship of the Roman management of military and civil administration. She focuses, in particular, on the financial, agricultural, industrial and trade dimensions of Rome. Following Mattingly (2013), Czarniawska insists on the 'hybridity' of the organization of the empire and especially its economy. We see the Empire through the eyes of Czarniawska as a hybrid military-economical conundrum, with a multiplicity of rules and standards interpreted locally and dependent on complex political and cultural practices of rules, bureaucracies and standards. After an in-depth analysis of a variety of approaches to these practices, Czarniawska offers a provocative set of analogies between ancient and contemporary organizing. The reader learns much from Czarniawska's analysis of scholarly discussions around the emergence of such contemporary managerial concepts as 'centralization' and 'bureaucratization'. The chapter concludes with a reflection on the limits and scope of using the Empire as a source of contemporary insight but, nonetheless, reinforces her key message that many of our ways of organizing were born in Rome.

The chapter by Wenjin Dai continues the exploration of ancient civilizations but introduces a non-Western tradition as a potential origin for organizational thought. Classical Chinese philosophy and, in particular, Daoism, Dai contends, can act as a source to enable scholars of management and organization studies (MOS) to develop an alternative origin of organizing and organizational theorizing that differs significantly from the mainstream. In her pursuit of this argument, Dai traces the historical emergence of constructions of an East/West divide, pointing out that differences originating in physical geography are now transcended by those of worldview. The representational work that goes into establishing and maintaining the East/West difference often positions Chinese thinking as mysterious and obtuse, contrasting it with the scientific rationality and empiricism of Western ontologies and epistemologies. As cracks have begun to appear in Western rationality and scientism, however, Chinese philosophies (as well as those of the Orient more generally) have become more fashionable. 'Fuzzy thinking', for example, lends itself to interpretation through the relational interaction of yin and yang; and a lexicon of Chinese terms - guanxi, renqing, wuwei have attracted the interest of those who see the need to pose indigenous challenges to Western ways of seeing. However, the fashion for all things Chinese itself invites critique. There are broad tendencies in the MOS literature to both simplify differences between East and West and to romanticize Chinese thought. As Dai poetically puts it, 'a splash of "Daoism" or a pinch of "Confucianism" adds oomph and an enticing 
"oriental" flavour'. She is highly critical of Hofstede-style studies that caricature 'Chinese values' and also finds fault in what she sees as Robert Chia's essentialist rendering of Chinese thought. Drawing inspiration from the work of the Chinese classics scholar, François Jullien, she argues that interested MOS scholars would do well to develop closer readings of the philosophical positions represented in Confucian and Daoist literatures. Through a discussion of Laozi's Dao De Jing (道德经) and other Daoist writings, Dai holds out the prospect of an epistemology which could act as a non-romanticized alternative origin of organizing; one that embraces the non-essentialism of the ineffable Dao.

Jose Bento da Silva and Ioanna Iordanou's chapter transports us forwards in time from ancient civilizations to a distinct (historical) epoch, the sixteenth century, from which we are able to apprehend seminal ideas of organizing and the emergence of a new managerial mindset. The chapter starts by offering a rationale as to why Jesuit and Venetian forms of organizing are important to reflect upon with regard to the 'origins of organizing'. This is followed by an overview of previous historical studies of the Society of Jesus and the Venetian Central Intelligence Agency and their relation to organizing and organization theory. Bento da Silva and Iordanou also claim that Jesuit and Venetian organizing could be understood through the lens of selected Foucauldian concepts. Indeed, discourses of power and governmentality emerge in their argument as ways of imagining Jesuits and Venetian practices of organizing as equivalent to managing. Even the origins of the concept of 'organizing', if situated in the sixteenth century, could be theorized in terms of 'governmental management'. The authors lead us to see in Jesuits and Venetians the origins and genealogical rise of managerialist practices and assemblages, asserting boldly that the emergence of modern governmentality cannot be detached from the emergence of modern managerialism. One of the key insights offered in this chapter is that 'governmentality', in a Foucauldian sense, emerges precisely at this moment in the sixteenth century as a contrast to the heretofore dominant idea of a sovereign monarch (as typified, for example, in Machiavelli's The Prince).

Moving to the era of industrial modernity, Donncha Kavanagh and Martin Brigham present Quakers as a prominent religious and societal movement that should be credited with introducing several pioneering innovations to modern organizing. Quakers were originally a nonconformist Protestant Christian community, whose beliefs centred on the idea of egalitarian unity of humans before God. As Kavanagh and Brigham astutely describe in their chapter, Quakers carried their philosophy of liberal individualism and this-worldly interest to human 
betterment to the domains of science, technology and commerce, introducing a number of innovations into practice and the moral philosophy of organizing. Quakers were active in establishing business corporations already before the ascent of the organized capitalism. Their willingness for experimentation, coupled with a management philosophy emphasizing efficiency and simplicity, paved a way for a series of successful businesses across sectors such as finance, engineering and manufacturing. However, after World War I, Quakers lost interest in pursuing their programme of social reform through business activities and, as a result, most of the companies became mainstream capitalist corporations with institutionalized formal hierarchies. Yet it is rarely understood that some of the leading present-day corporations in the UK share a Quaker origin, including for example Barclays, Cadbury-Rowntree and Price Waterhouse. The Quaker style of organizing was ahead of its time. Kavanagh and Brigham present an impressive catalogue of management techniques that Quakers initiated. These include not only rationalistic methods, such as formal accounting and functional organizational form, but also humanistic and democratic practices like employee welfare programmes, lifelong education of workers, works councils and profit sharing. It is this curious combination of a rationalistic attitude toward efficiency and scientific progress and a commitment to employee well-being and the wider common good that demonstrates the unique ethical and philosophical background of the Quaker movement. Quakers demonstrate through their idiosyncratic philosophy of a liberal Protestant ethos how business organizations can advocate a Tayloristic pursuit of efficiency and systematization of organizing while at the same time striving for the greater good of society. As forgotten pioneers who demonstrated a unique rapprochement between rational modernity and traditional religious morality, Quakers could offer a radically different understanding of the origin of modern ideas of managing.

Taken together, the chapters in this book paint a rich picture of the many possible roots and foundations for the theory and practice of organizing. But is there any hope of a rapprochement or synthesis amongst the various times and places that the authors in this collection introduce as the suggestive beginnings of organizing and organizations? Could there be an 'origin of origins'? Tempting as it may be to search for the ultimate root of organizing, this is precisely the attitude that this book intends to challenge. Instead of an uncontested origin, it is more likely that there is a multitude of largely incommensurable beginnings and traditions that can serve as foundations for our understanding of organizing and organized existence. Hence the word 'origins' (plural) in the book's title, Origins of Organizing, refers to a potentially unlimited set of 
different sources for imagining, conceptualizing and doing organizing. Or, as Gibson Burrell (2001: 20) has so robustly articulated in an earlier essay: 'It is a tale of many cities. Of avenues explored and then abandoned. Of cul de sacs which become open highways. Of brute force and ignorance. Of possibilities and potentials. It is, perhaps, only in understanding its genealogy that one can appreciate how contested "organization" is as an idea.' Our hope is that this volume will inspire new explorations into complementary practices and traditions that so far have remained in the shadow of mainstream ideas about the origins of organizing.

\section{REFERENCES}

Adler, Paul (Ed.) (2009). The Oxford handbook of sociology and organization studies: Classical foundations. New York: Oxford University Press.

Barley, Stephen R. and Kunda, Gideon (1992). Design and devotion: Surges of rational and normative ideologies of control in managerial discourse. Administrative Science Quarterly, 37(3), 363-99.

Bendix, Reinhard (1974). Work and authority in industry: Ideologies of management in the course of industrialization. Berkley, CA: University of California Press.

Burrell, Gibson (2001). Ephemera: Critical dialogues on organization. Ephemera: Critical Dialogues on Organization, 1(1), 11-29.

Case, Peter and Brohm, Rene (2012). Buddhist belief and living ethics. In: P. Case, H. Höpfl and H. Letiche (Eds), Belief and organization (pp. 51-68). Basingstoke: Palgrave Macmillan.

Casey, Catherine (2002). Critical analysis of organizations: Theory, practice, revitalization. London: Sage.

Chia, Robert (2003). From knowledge-creation to the perfecting of action: Tao, Basho and pure experience as the ultimate ground of knowing. Human Relations, 56(8), 953-81.

Cummings, Stephen and Bridgman, Todd (2011). The relevant past: Why the history of management should be critical for our future. Academy of Management Learning and Education, 10(1), 77-93.

Czarniawska, Barbara (2014). A theory of organizing. Cheltenham, UK and Northampton, MA: Edward Elgar Publishing.

Dobbs, Remi (2013). A critical history of management thought. Solidarité: Journal of the Radical Left, September-October, 8-32.

Drucker, Peter, Kanter, Rosabeth and Graham, Pauline (1995). Mary Parker Follett: Prophet of management: A celebration of writings from the 1920s. Boston, MA: Harvard Business School Press.

Foucault, Michel (1972). The archaeology of knowledge. London: Tavistock.

George, Claude S. (1968). The history of management thought. Englewood Cliffs, NJ: Prentice-Hall. 
Guillén, Mauro F. (1994). Models of management: Work, authority and organization in a comparative perspective. Chicago, IL: University of Chicago Press.

Hatch, Mary Jo and Cunliffe, Ann (2006). Organization theory: Modern, symbolic and postmodern perspectives. Oxford: Oxford University Press.

Hinings, Robert and Greenwood, Royston (2002). ASQ forum: Disconnects and consequences in organization theory? Administrative Science Quarterly, 47(3), 411-21.

Hofstede, Geert (1983). The cultural relativity of organizational practices and theories. Journal of International Business Studies, 14(2), 75-89.

Jacques, Roy (1996). Manufacturing the employee: Management knowledge from the 19th to 21st centuries. London: Sage.

Jacques, Roy (2006). History, historiography and organization studies: The challenge and the potential. Management and Organizational History, 1(1), 31-49.

Kieser, Alfred (1987). From asceticism to administration of wealth: Medieval monasteries and the pitfalls of rationalization. Organization Studies, 8(2), 103-23.

Kieser, Alfred (1989). Organizational, institutional, and societal evolution: Medieval craft guilds and the genesis of formal organizations. Administrative Science Quarterly, 34(4), 540-64.

Kuhn, Thomas (1962). The structure of scientific revolutions. Chicago, IL: University of Chicago Press.

Laurent, Andre (1986). The cross-cultural puzzle of international human resource management. Human Resource Management, 25(1), 91-102.

Mattingly, David (2013). Imperialism, power, and identity. Princeton, NJ: Princeton University Press.

Mills, Albert J., Weatherbee, Terence G., and Durepos, Gabrielle (2014). Reassembling Weber to reveal the-past-as-history in management and organization studies. Organization, 21(2), 225-43.

Morgan, Gareth (1986). Images of organization. London: Sage.

Reed, Mike (2006). Organizational theorizing: A historically contested terrain. In: Stewart R. Clegg, Cynthia Hardy, Thomas B. Lawrence and Walter R. Nord (Eds), The Sage handbook of organization studies (pp. 19-54). London: Sage.

Scott, W. Richard and Davis, Gerald F. (2006). Organizations and organizing: Rational, natural, and open system perspectives. Upper Saddle River, NJ: Pearson.

Skinner, Quentin (1969). Meaning and understanding in the history of ideas. History and Theory, 8(1), 3-53.

Spoerhase, Carlos (2008). Presentism and precursorship in intellectual history. Culture, Theory and Critique, 49(1), 49-72.

Starbuck, William H. (2003). The origins of organization theory. In: H. Tsoukas and C. Knudsen (Eds), The Oxford handbook of organization theory (pp. 14382). Oxford: Oxford University Press. 
Tsoukas, Haridomos (2003). New times, fresh challenges: Reflections on the past and the future of organization theory. In: H. Tsoukas and C. Knudsen (Eds), The Oxford handbook of organization theory (pp. 607-22). Oxford: Oxford University Press.

Weick, Karl E. (1969). The social psychology of organizing. Reading, MA: Addison-Wesley.

White, Hayden (1973). Metahistory: The historical imagination in nineteenth century Europe. New York and Baltimore, MD: Johns Hopkins University Press.

Witzel, Morgen (2012). A history of management thought. London: Routledge.

Wren, Daniel A. and Bedeian, Arthur G. (2009). The evolution of management thought. Hoboken, NJ: John Wiley and Sons. 